\title{
Análise foliar de Urochloa decumbens e identificação de plantas invasoras em área de recuperação de depósito de metalurgia de zinco
}

Ailton Batista Oliveira Junior ${ }^{1}$ Maria Auxiliadora Pereira Figueiredo ${ }^{2}$ Cristiane Alves Fogaça ${ }^{1}$ Luiz Henrique Arimura Figueiredo ${ }^{1 *}$ Adolf Heinrich Horn ${ }^{3}$

${ }^{1}$ Universidade Estadual de Montes Claros Departamento de Ciências Agrárias Avenida Reinaldo Viana, 2630 Janaúba MG 39404-547

2 Universidade Federal de Minas Gerais Instituto de Ciências Agrárias Avenida Universitária, 1000 Montes Claros. MG 39440-000.

${ }^{3}$ Universidade Federal de Minas Gerais Instituto de Geociências Departamento de Geologia Av. Antônio Carlos, 6627 Av. Antônio Carlos, 6627
Belo Horizonte, MG 31270-010

*Autor para correspondência: luiz.figueiredo@unimontes.br

\section{RESUMO}

As indústrias metalúrgicas geram grande quantidade de resíduos sólidos, podendo causar impactos ambientais negativos. Objetivou-se nesse estudo caracterizar os níveis de metais presentes nas folhas da Urochloa decumbens e identificar as plantas invasoras na área do antigo depósito de rejeitos de metalurgia de zinco. A área selecionada foi a PH9 que possui 14,4 ha e está situada no município de Três Marias - MG. Para a coleta das amostras de solo foi adotado o caminhamento em dois sentidos, norte - sul e leste - oeste, totalizando 29 pontos amostrais georreferenciados e distanciados um do outro a cada 20 metros. Em cada ponto, foi realizada a coleta de folha Urochloa decumbens, que foram acondicionadas em sacos de papel e levadas ao Laboratório da Unimontes, Campus Janaúba - MG, onde foi realizada a digestão nitro perclórica e em seguida transportadas ao Laboratório da UFMG - Campus Belo Horizonte para a realização das análises por ICP-OES. As plantas invasoras foram coletas realizando caminhamento aleatório pela área total. O método estatístico utilizado para o tratamento dos dados foi a análise descritiva, observando os valores dos elementos de cada ponto amostral do solo, destacando os valores máximos, médios, mínimos e totais. As plantas de Urochloa decumbens apresentaram elevados teores de $\mathrm{Ca}, \mathrm{Mg}$ e $\mathrm{Fe}$ nas folhas. Os teores de $\mathrm{Zn}$, no entanto, estavam abaixo do ideal para as plantas de Urochloa decumbens. Foram identificadas na área, nove espécies invasoras arbustivas, compondo um total de seis famílias, sendo a Gramínea a principal delas.

Palavras chave: análise foliar, plantas invasoras, magnésio.

\section{ABSTRACT}

The metallurgical industries generate large amount of solid waste, which can cause negative environmental impacts. The objective of this study was to characterize the metal levels present in the leaves of Urochloa decumbens and to identify the invasive plants in the area of the old zinc metallurgy tailings deposit. The selected area was PH9, which has 14.4 ha and is located in Três Marias - MG. Soil samples were collected by two - way walk, north - south and east - west, totaling 29 georeferenced sampling points and 20 meters apart. At each point, the Urochloa decumbens leaf was collected, placed in paper bags and taken to the Unimontes Laboratory, Campus Janaúba MG, where the nitro perchloric digestion was performed and then transported to the UFMG Laboratory - Campus Belo Horizonte for ICP-OES analysis. The invasive plants were collected by performing random walk through the total area. The statistical method used for 
data treatment was descriptive analysis, observing the values of the elements of each soil sampling point, highlighting the maximum, average, minimum and total values. Urochloa decumbens plants presented high levels of $\mathrm{Ca}, \mathrm{Mg}$ and $\mathrm{Fe}$ in the leaves. Zn contents, however, were below ideal for Urochloa decumbens plants. Nine shrub invasive species were identified in the area, making up six families, being the main one.

Keywords: leaf analysis, invasive plants, magnesium.

\section{INTRODUÇÃO}

O zinco é um dos metais não ferrosos mais consumidos no mundo, possuindo vasta gama de aplicações. Após a extração do minério de esfarelita $(\mathrm{ZnFeS})$, inicia-se o seu beneficiamento por meio do processo denominado "Roasting-leaching-electrolysis" ou "Ustulação-lixiviação-eletrólise", usado por cerca de $85 \%$ das usinas de metalurgia do mundo (BRASIL, 2011).

Durante esse processo o minério passa por inúmeras etapas. Segundo Feijó (2007) o material passa por um procedimento que visa a solubilização e a remoção de compostos de cálcio e magnésio. Após este estágio, o material segue para a etapa conhecida como "Tratamento do Magnésio", e posteriormente para a etapa de "Flotação", ambas visam à solubilização do cálcio e magnésio que não foram removidos pela etapa anterior.

Durante o processo de Lixiviação Neutra ocorre a formação de resíduos na forma de ferrita de zinco e de óxidos metálicos que são retirados posteriormente pela etapa de Lixiviação Ácida. No processo de purificação ocorre a remoção de alguns subprodutos e rejeitos, como o $\mathrm{Cu}$ e o $\mathrm{Fe}$ (LEVESQUE; ZABINSKI, 2010; QIAO et al., 2013) que são as principais impurezas e muito prejudiciais a este processo.

Ao final de todos os processos, a polpa rica em impurezas é separada em filtrado e torta. $\mathrm{O}$

\section{MATERIAL E MÉTODOS}

A área selecionada para o estudo foi a de um antigo depósito de resíduos de metalurgia de zinco, denominada Área PH9, possuindo aproximadamente 14,4 ha; $400 \mathrm{~m}$ no sentido norte-sul e $360 \mathrm{~m}$ no sentido leste-oeste. Ela está situada no município de Três Marias MG, localizada na região centro norte do Esta- filtrado retorna novamente ao processo e a torta é encaminhada para a barragem de rejeitos. Esta apresenta resíduos dos processos aos quais o material foi submetido. Geralmente é rica em $\mathrm{Ca}, \mathrm{Mg}, \mathrm{Al}, \mathrm{Fe}, \mathrm{Mn}, \mathrm{Cu}$ e $\mathrm{Zn}$ (JANG et al., 2013; NGENDA et al., 2009; SAFARZADEH et al., 2009). Ressalte-se que o $\mathrm{Mg}$ (na forma de $\mathrm{MgO}$ e/ou $\mathrm{MgCO}_{3}$ ), em concentrações superiores a $300 \mathrm{mg} / \mathrm{L}$, pode causar danos ao solo e à vegetação circundante segundo estudo realizado pelo laboratório DALE COWN AGRI-FOOD LAB (FU et al., 2011; MACHIN; NAVAS, 2000).

A Urochloa decumbens (Syn. Brachiaria decumbens) conhecida popularmente como capim-braquiária, apresenta facilidade de semeadura, crescimento rápido e baixa exigência em fertilidade do solo (SILVA 2008). A regeneração natural de uma área degrada pode ocorrer, sendo muito afetada pelas condições edáficas, banco de sementes e fragmentos no entorno (MARTINS et al., 2014).

Objetivou-se nesse estudo caracterizar os níveis de metais presentes nas folhas da Urochloa decumbens e identificar as plantas invasoras na área do antigo depósito de rejeitos de metalurgia de zinco.

do, dentro da bacia do rio São Francisco, nas coordenadas geográficas $18^{\circ} 12^{\prime} 21^{\prime}$ " de latitude

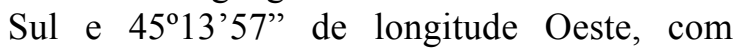
altitude de 569 metros. O clima Aw segundo a classificação de Köppen é caracterizado como clima tropical, quente e úmido, apresentando inverno seco e verão chuvoso (OMETTO,1981) 
A temperatura média anual é de $23,5^{\circ} \mathrm{C}$, cujo mês mais quente do ano é fevereiro com temperatura média de $25,4{ }^{\circ} \mathrm{C}$ e o mês que apresenta temperaturas mais baixas é junho, com temperatura média de $20,6{ }^{\circ} \mathrm{C}$. A precipitação média anual é de $1214 \mathrm{~mm}$, cujo mês de dezembro é o de maior precipitação, com média de $250 \mathrm{~mm}$ e o mês de agosto é o mês mais seco, com média de $3 \mathrm{~mm}$. A vegetação nativa da região é constituída predominantemente pelo Cerrado, com gramíneas, arbustos e árvores.
O caminhamento amostral adotado foi no sentido norte - sul (NS) e outro no sentido leste - oeste (EW) de acordo a declividade e tamanho da área amostral (Figura 1). No sentido norte - sul (sentido de maior comprimento) foram coletadas 16 amostras, e no sentido leste - oeste (sentido de menor comprimento) 13 amostras, totalizando 29 pontos amostrais georreferenciados e distanciados a cada 20 metros, para maior representatividade amostral.

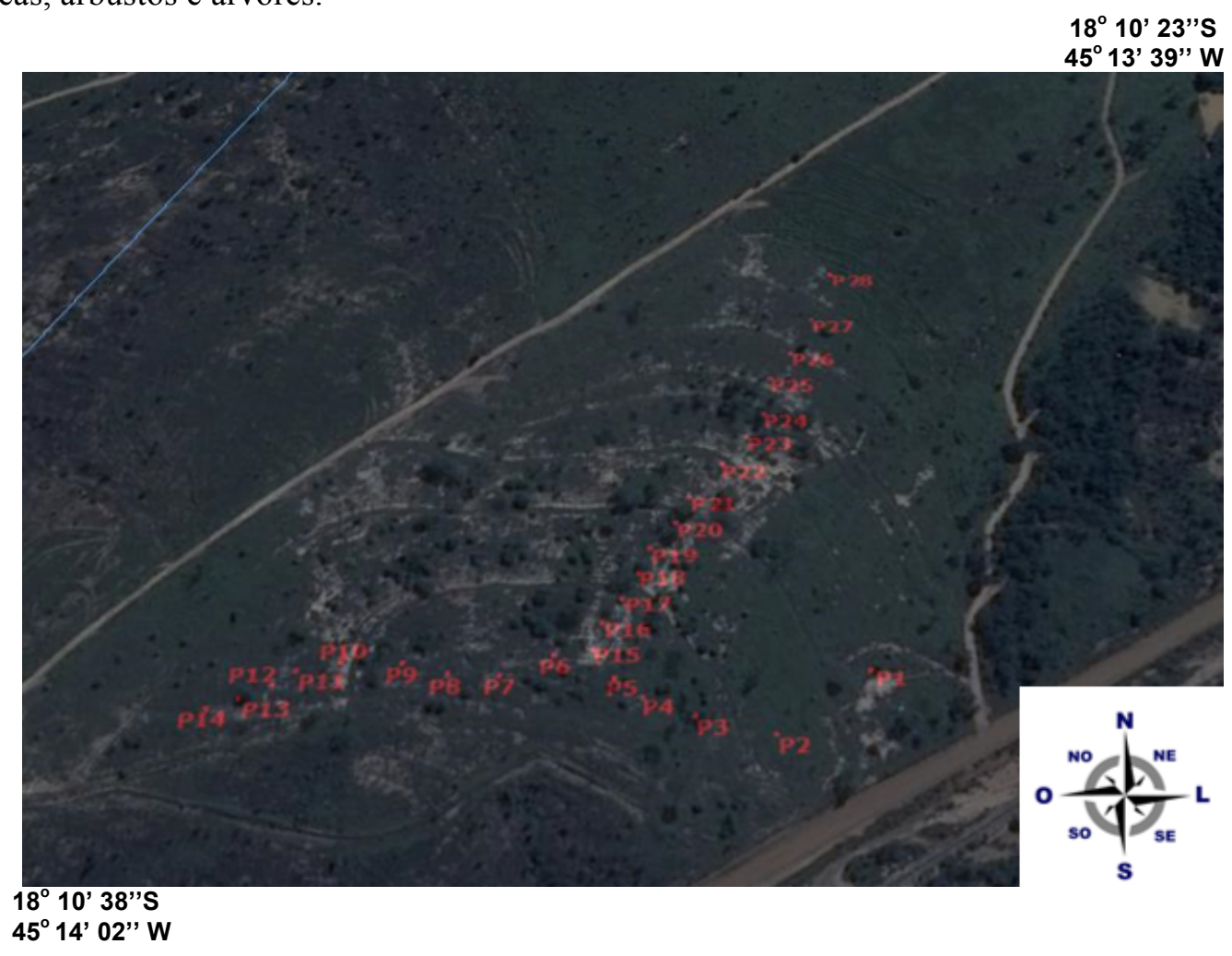

Figura 1 Croqui da área PH9 da empresa VOTORANTIM em Três Marias com os pontos de amostragem.

Em cada ponto foi realizada a coleta do capim-braquiária (uma planta por ponto) e quando não havia a ocorrência da forrageira, era coletada, então, a planta mais próxima do ponto. As plantas foram acondicionadas em sacos plásticos, identificados, vedados e transportados ao Laboratório de Análise de Rotina de Solos da Unimontes, Campus Janaúba - MG. No laboratório realizou-se a retirada da terceira folha, completamente expandida, e estas folhas foram novamente acondicionada em sacos plásticos, identificados, vedados e transportados ao Laboratório da Universidade Federal de
Minas Gerais - UFMG - Campus Belo Horizonte para a realização das análises químicas. Foi realizada a análise somente da folha, pois no caso do capim-braquiária, há um acúmulo homogêneo dos valores na parte superior (folha) e na parte inferior (raiz). Foi realizada a digestão nitroperclórica $\left(\mathrm{HNO}_{3}-\mathrm{HClO}_{4}\right)$ e determinados os elementos $\mathrm{Ca}, \mathrm{Mg}, \mathrm{Zn}, \mathrm{Fe}, \mathrm{Mn}, \mathrm{Cu}$ por ICP OES.

Foi realizado um levantamento da vegetação arbustivas, que ocorrem na área PH9, usando a metodologia do caminhamento aleatório, sendo coletas amostras da parte vegetativo e se possível 
com flor, para a confecção de exsicatas. Foram realizadas 3 viagens para coleta de matérias vegetais durante um ano. As plantas foram coletadas e levadas para identificação no herbário da

\section{RESULTADOS E DISCUSSÃO}

Os resultados de Ca são apresentados na Figura 2. Os valores variam de $12,47 \mathrm{~g} / \mathrm{kg}$ no ponto $\mathrm{P} 17$ a $45,44 \mathrm{~g} / \mathrm{kg}$ no ponto $\mathrm{P} 29$, apresentando valor médio de $26,07 \mathrm{~g} / \mathrm{kg}$ demonstrando grande amplitude nos dados.
UNIMONTES. A identificação das espécies foi realizada em consulta a especialistas e em comparação com material de herbário e em sites especializados.
Em todos os pontos amostrados, os valores são considerados extremamente altos (Malavolta et al., 1997), sendo que em 11 pontos os valores foram iguais ou superiores ao valor médio.
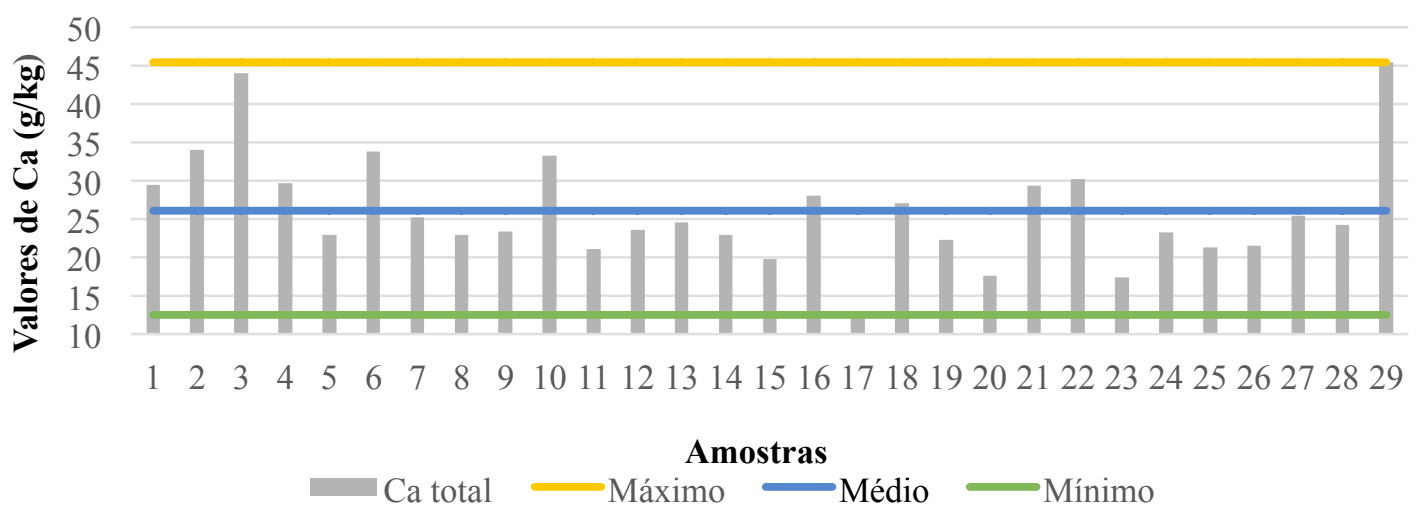

Plantas que apresentam altos teores de cálcio resistem melhor à toxidez por alumínio, cobre e manganês, entretanto podem induzir a deficiência de magnésio e alteração do ritmo de divisão celular da planta (Prado, 2008). A maior parte do cálcio na planta está localizada nas paredes celulares e sua concentração no citoplasma é bastante baixa, sendo armazenado no vacúolo nas formas de oxalatos ou carbonatos, como estratégia de tolerância e para outras funções como ativador enzimático (Fernandes, 2006).

Os valores de Magnésio nas folhas variaram de $19,72 \mathrm{~g} / \mathrm{kg}$ no ponto $\mathrm{P} 3 \mathrm{a}$ $20,72 \mathrm{~g} / \mathrm{kg}$ no ponto $\mathrm{P} 1$, apresentando valor médio de 26,63 g/kg (Figura 3) demonstrando baixa heterogeneidade. Em todos os pontos amostrados os valores foram considerados extremamente altos (Malavolta, 1997), indicando uma nutrição provavelmente não balanceado, pois $\mathrm{o}$ excesso provoca interferências na absorção de cálcio e potássio (Fernandes, 2006). Os valores apresentam pequena amplitude, demonstrando que independentemente do teor do elemento no solo, a planta regula sua entrada.

Resultados semelhantes foram observados por Ahmed et al. (2014) que observaram efeito deletério na qualidade do solo e no crescimento das plantas. Resultados estes confirmados por Wang et al. (2015) que demonstraram que a deficiência de cálcio é a principal causa que dificulta o crescimento das plantas. Em solos com altos teores de magnésio em relação ao cálcio, contudo, os mecanismos responsáveis pela supressão desse crescimento ainda não são claros.

Os valores de alumínio apresentaram grande amplitude nos dados, variando de $2,98 \mathrm{~g} / \mathrm{kg}$ no ponto P29 a $26,00 \mathrm{~g} / \mathrm{kg}$ no ponto $\mathrm{P} 8$, com média de $8,31 \mathrm{~g} / \mathrm{kg}$. A maioria dos pontos apresentou valores acima da média (Figura 4). 


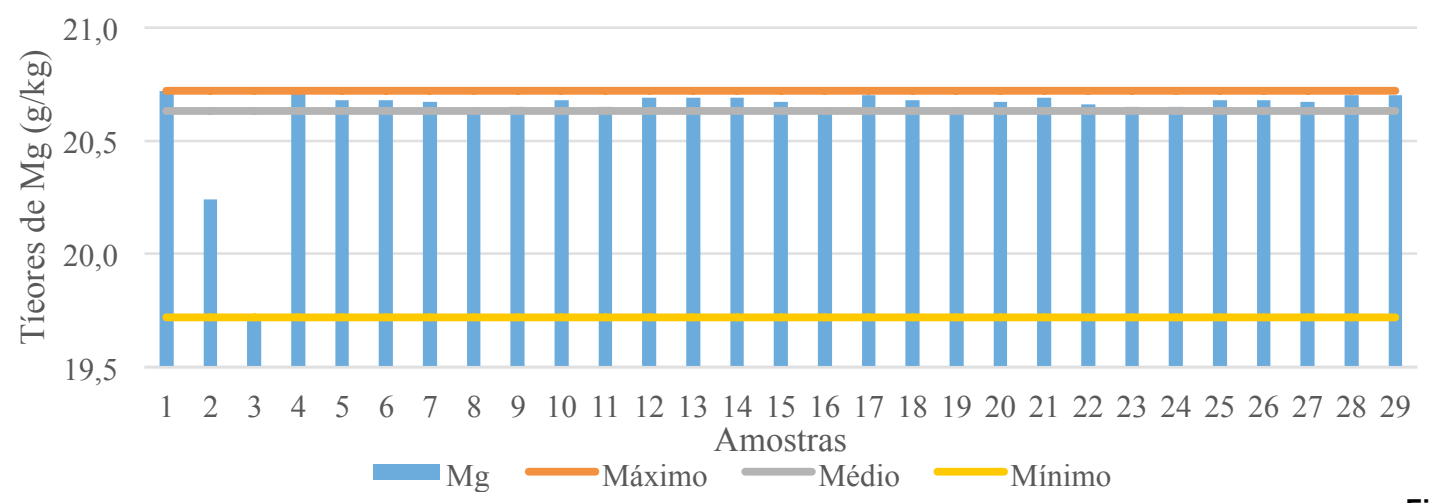

Figura 3

Valores de magnésio nas folhas da forrageira da área PH9.

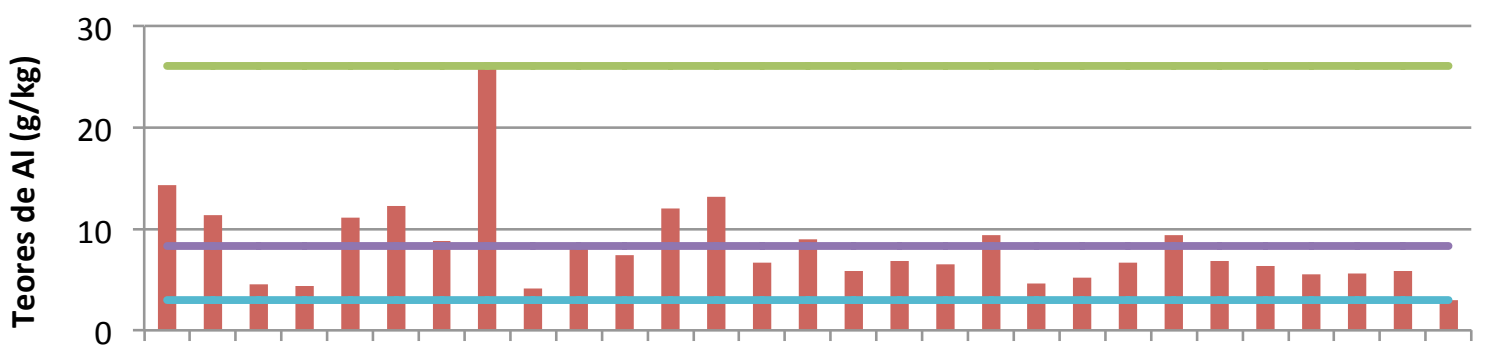

$142 \quad 3 \quad 4 \quad 5 \quad 6 \quad 7 \quad 8 \quad 9 \quad 1011121314151617181920212223242526272829$

Amostras

Al Al mínimo Al máximo - Al médio

Figura 4

Valores de alumínio nas folhas da forrageira da área PH9.

Evidências bioquímicas indicam que o alumínio absorvido liga-se ao fósforo por reação de adsorção-precipitação na parede das células epidérmicas e corticais e parte pode também penetrar nas células do tecido meristemático e interferir na divisão celular, no alongamento da raiz, na respiração, na atividade de $\mathrm{ATP}^{\prime}$ ases, no teor de aminoácidos, na permeabilidade da membrana plasmática, na fosforilação dos açúcares e de fosfatasses ácidas, na fotossíntese e na absorção de água e de nutrientes (Fernandes, 2006).

No caso do ferro os valores variaram de $4,84 \mathrm{~g} / \mathrm{kg}$ no ponto $\mathrm{P} 4$ à $26,67 \mathrm{~g} / \mathrm{kg}$ no ponto P8 (Figura 5), apresentando valor médio de $10,94 \mathrm{~g} / \mathrm{kg}$ demonstrando baixa heterogeneidade. Os valores na maioria dos pontos foram considerados altos (Malavolta et al., 1997). A absorção pelas plantas foi considerada alta mesmo quando os valores disponíveis no solo eram baixos, pois a absorção é metabolicamente controlada, podendo ser absorvido como $\mathrm{Fe}^{3+}, \mathrm{Fe}^{2+}$ e Fe-quelato e a capacidade das

raízes em reduzir $\mathrm{Fe}^{3+}$ para $\mathrm{Fe}^{2+}$ parece ser fundamental na absorção deste cátion por muitas plantas (Fernandes, 2006).

Os valores de manganês variaram de $0,55 \mathrm{~g} / \mathrm{kg}$ no ponto $\mathrm{P} 1 \mathrm{a} 3,29 \mathrm{~g} / \mathrm{kg}$ no ponto $\mathrm{P} 10, \quad$ com média de $1,62 \mathrm{~g} / \mathrm{kg}$ demonstrando grande amplitude nos dados (Figura 6). O teor nas folhas não é considerado tóxico (Malavolta et al., 1997), mesmo quando observados altos valores disponíveis na área, pois a absorção é caracterizada como um processo bifásico. A fase de captação inicial e rápida é reversível e não metabólica e a segunda fase é lenta, com $\mathrm{Mn}^{2+}$ sendo menos facilmente trocado (Fernandes, 2006).

No caso do Cobre os valores variaram de $0,027 \mathrm{~g} / \mathrm{kg}$ no $\mathrm{P} 6$ a $0,1717 \mathrm{~g} / \mathrm{kg}$ no $\mathrm{P} 29$, com média de $0,063 \mathrm{~g} / \mathrm{kg}$ (Figura 7), apresentando pouca heterogeneidade. Em todos os pontos observaram-se baixos valores de cobre na planta, não causando toxidez (Malavolta, 1997). 


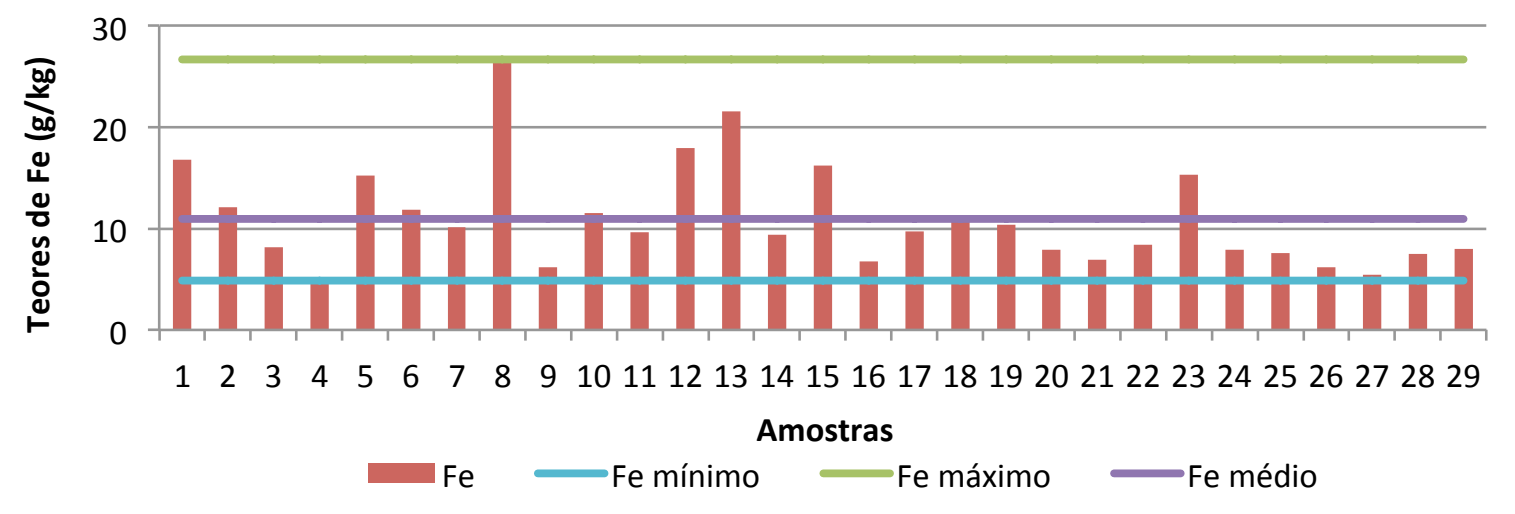

Valores de ferro nas folhas da forrageira 5

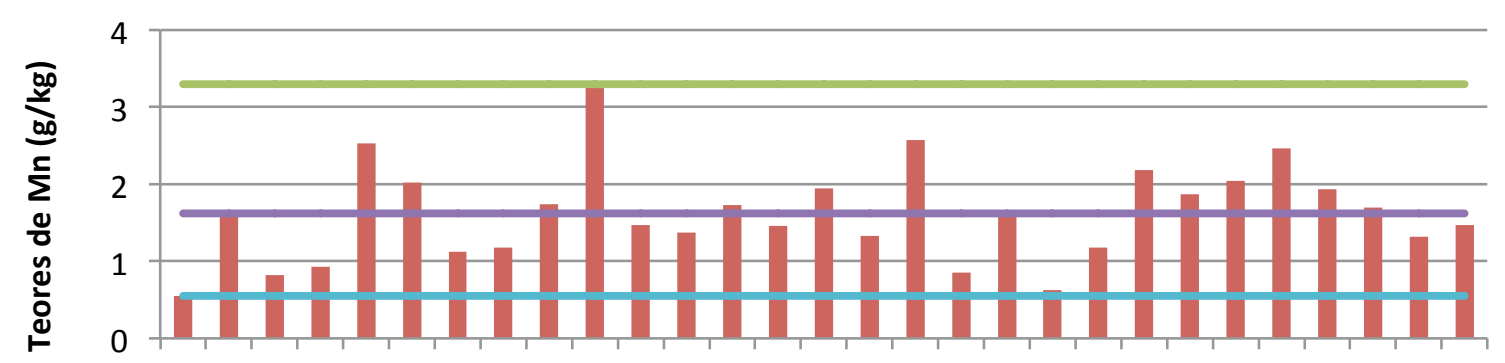

$1 \quad 2 \quad 3 \quad 4 \quad 5 \quad 6 \quad 7 \quad 8 \quad 9 \quad 1011121314151617181920212223242526272829$

Amostras

Mn $\longrightarrow$ Mn mínimo Mn máximo $\quad$ Mn médio

Figura 6

Valores de manganês nas folhas das plantas da área PH9.

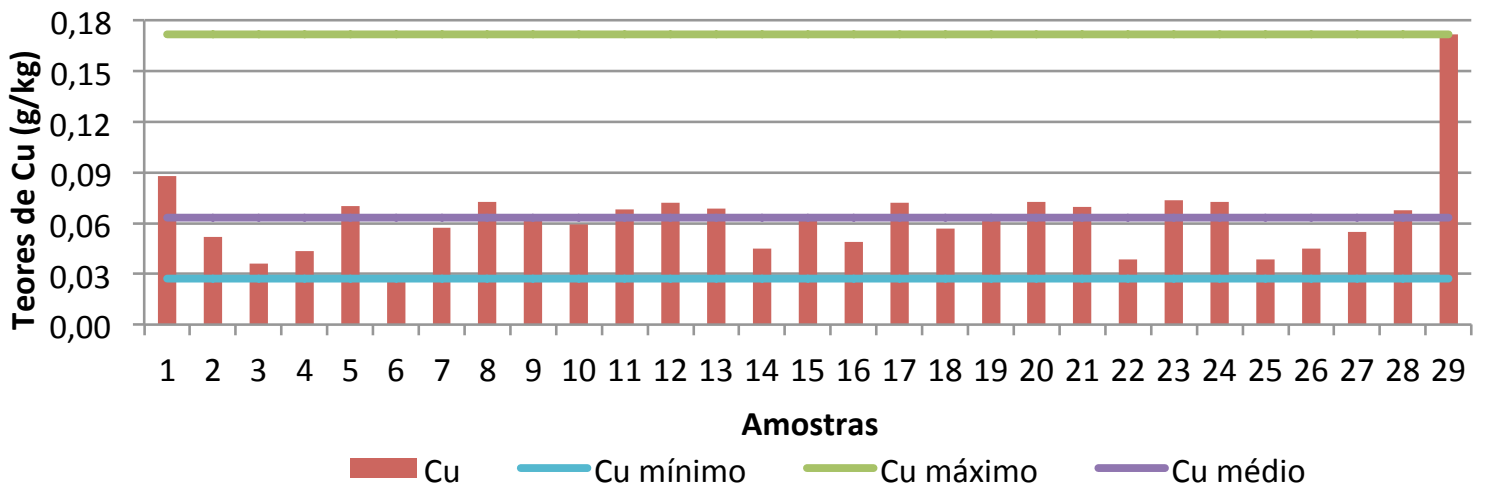

Figura 7

Valores de cobre nas plantas da área PH9.

Os valores de zinco variaram de 1,58 $\mathrm{g} / \mathrm{kg}$ no ponto P26 a $9,35 \mathrm{~g} / \mathrm{kg}$ no ponto P16, apresentando média de $2,99 \mathrm{~g} / \mathrm{kg}$ (Figura 8) demonstrando alta amplitude. O teor de zinco considerado ideal para as plantas é de $20 \mathrm{~g} / \mathrm{kg}$ (Malavolta, 1997). Em todos os pontos foram observados valores abaixo desse elemento. De forma geral, na área não se encontraram plantas com teores acima da concentração tóxica de zinco. 


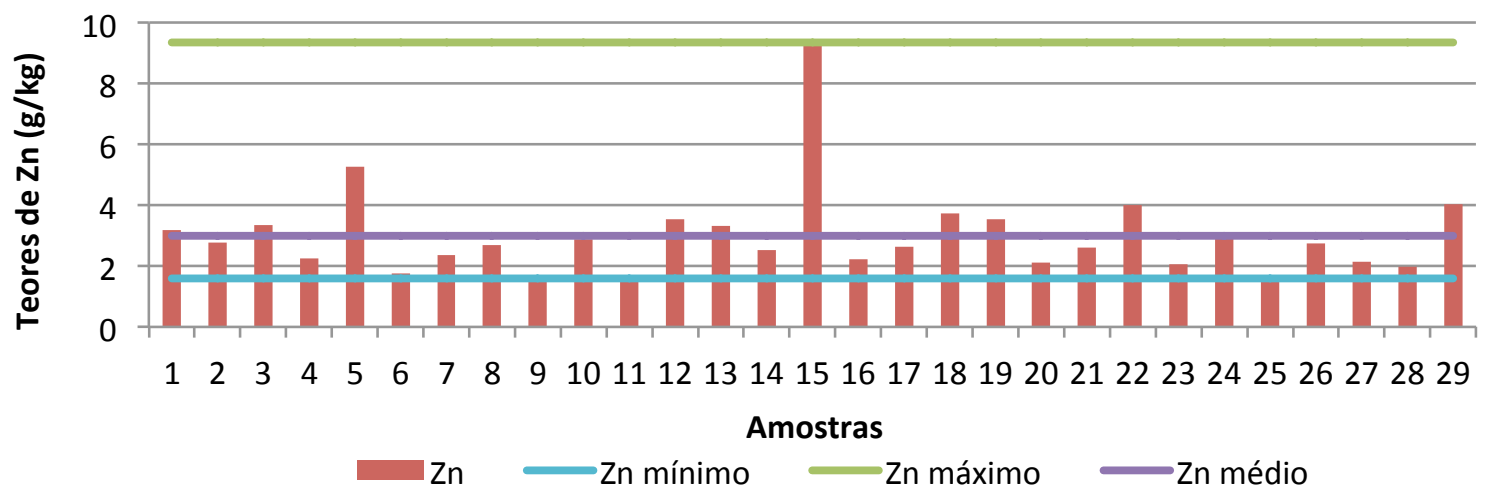

FIGURA 8: Valores de zinco nas folhas da forrageira das plantas da área PH9.

$\mathrm{Na}$ área PH9 foram identificadas nove espécies arbustivas diferentes (Tabela 1), sendo que a Taboa e a Largatixa são aquáticas e estão presentes nas bacias de contenção dos terraços. Das espécies encontradas apenas a Braquiarinha foi plantada pela empresa há mais de 20 anos, como uma forma de recuperar a área. Das noves espécies, seis são utilizadas para a implantação de pastagens.

Foram identificadas seis famílias, sendo a Gramineae a família mais comum. Carneiro et al. (2002) relataram que as gramíneas de modo geral, têm potencial para serem utilizadas em programas de recuperação de áreas contaminadas devido à relativa facilidade de se estabelecerem e assim promover uma rápida $\mathrm{e}$ densa cobertura do solo, melhorando a estrutura física, atenuando processos erosivos e adicionando matéria orgânica. Silva (2008) afirma que as gramíneas não são consideradas plantas hiperacumuladora. Entretanto elas conseguem acumular quantidades consideráveis de metais pesados, além de serem espécies hospedeiras universais de fungos micorrízicos arbusculares (FMAs).

Com a identificação das plantas, foi possível verificar a baixa diversidade de espécies presentes, devido a alta concentração de sais no solo e também foi possível verificar que a maioria das plantas presentes se desenvolveram somente em cima das fezes deixados por animais.

Tabela 1: Plantas arbustiva identificadas na área $\mathrm{PH} 9$

\begin{tabular}{ccc}
\hline Nome cientifico & Nome vulgar & Família \\
\hline Brachiaria decumbens & Braquiarinha & Gramineae \\
Macroptilium atropurpureum & Siratro & Leguminosa \\
Echinochloa polystachya & Capim Navalha & Ciperaceae \\
Paspalum notatum & Grama batatais & Gramineae \\
Panicum maximum & Capim colonião & Gramineae \\
Cynodon dactylon & Grama Bermuda & Gramineae \\
Senna obtusifolia & Fedegoso & Leguminosa \\
Typha augustifolia & Taboa & Typhaceae \\
Sagittaria guianensis & Largatixa & Alismataceae \\
\hline
\end{tabular}

\section{CONCLUSÕES}

As plantas de Brachiaria decumbens apresentaram elevados teores de Cálcio, Magnésio e Ferro nas folhas. Os teores de Zinco estavam abaixo do ideal para as plantas de Brachiaria decumbens. Foram identificadas na área, nove espécies invasoras arbustivas, compondo um total de seis famílias, sendo a Gramínea a principal.

Observou-se que as principais limitações para uma revegetação são o $\mathrm{pH}$ alto, concentrações localmente elevadas de $\mathrm{Cu}$ e $\mathrm{Pb}$, a alta temperatura e a falta de material orgânica no substrato (argilito) compactado e denso. 


\section{REFERÊNCIAS}

AHMED, I.; RAO P.; HUSSEIN, M. Quality Assessment of Soil at municipal solid waste dumpsite and possibilities of reclamation of land. Int. J. Innovative Sci. Engin. \& Tech, 1(7), 274-294, 2014.

BRASIL. Ministério de Minas e Energia. Secretaria de Geologia, Mineração e Transformação Mineral. Departamento de Transformação e Tecnologia Mineral. Anuário Estatístico Setor Metalúrgico, p. 101-104, 2011.

CARNEIRO, M. A. C.; SIQUEIRA, J.O.; MOREIRA, F. M. S. Comportamento de espécies herbáceas em misturas de solo com diferentes graus de contaminação com metais pesados. Pesquisa Agropecuária Brasileira, 37(11), 1629-1638, 2002.

FEIJÓ, F. D. Redução das perdas de zinco associadas aos processos de purificação do licor por cementação e de tratamento dos resíduos gerados da Votorantin Metais. 178 p. Dissertação (Mestrado em Engenharia Metalúrgica e de Minas, Área de concentração de Hidrometalurgia) Universidade Federal de Minas Gerais. Belo Horizonte, 2007.

FERNANDES, M.S. Nutrição mineral de plantas. Sociedade Brasileira de Ciência do Solo. Viçosa. 432p. 2006.

FU, S.; LI, P.; FENG, Q.; LI, X.; LI, P.; SUN, J.; Chen, J. Soil quality degradation in amagnesite mining area. Pedosphere, 21(1), 98-106, 2011.

JANG, M. H.; CHO, H. W.; PARK, S. K.; HA, J. H. Microbial community structure in a thermophilic aerobic digester used as a sludge pretreatment process for the mesophilic anaerobic digestion and the enhancement of methane production. Bioresource Technology, 145, 80-89, 2013.

LEVESQUE, A.; ZABINSKI, P. Electrochemical corrosion behavior in $\mathrm{NaCl}$ medium of zinc-nickel alloys electrodeposited under applied magnetic field. Journal of Alloys and Compounds, 506(2), 575-580, 2010.

MACHIN, J.; NAVAS, A. Soil pH changes induced by contamination by magnesium oxides dust. Land Degradation \& Development, 11(1), 37-50, 2000.

MALAVOLTA, E.; VITTI, G. C.; OLIVEIRA, S. A. Avaliação do estado nutricional das plantas: princípios e aplicações. Piracicaba: POTAFOS: 319p. 1997.
MARTINS, R. U.; SANTOS-SILVA, A; GALILEO, M. H. M.; LIMEIRA-DEOLIVEIRA, F. Cerambycidae (Coleoptera) dos estados do Piauí e Ceará, Brasil: Espécies conhecidas, nova tribo, nova espécie e novos registros. Iheringia, Série Zoologia. 104(3), 373-384, 2014.

NGENDA, R. B.; SEGERS, L.; KONGOLO, K. B. Base metals recovery from zinc hydrometallurgical plant residues by digestion method. In: The SAIMM Southern African Hydrometallurgy Conference. 2008 Johanesburg, SAIMM p. 17-29, 2009.

OMETTO, J. C.. Bioclimatologia Vegetal. São Paulo: Editora Agronômica Ceres. 440 p. 1981

PRADO, R. M. Manual de nutrição de plantas forrageiras. Jaboticabal. FUNEP, 500 p. 2008.

QIAO, X.; LI, H.; ZSAO, W.; LI, D. Effects of deposition temperature on electrodeposition of zinc-nickel alloy coatings. Electrochimica Acta, 89, 771-777, 2013

SAFARZADEH, S.; RONAGHI, A.; KARIMIAN, N. Effect of cadmium toxicity on micronutrient concentration, uptake and partitioning in seven rice cultivars. Archives of Agronomy and Soil Science, 59(2), 231245, 2013.

SILVA, K. P. Estudo do reaproveitamento do resíduo gerado no processo hidrometalúrgico de fabricação de sulfato de zinco heptahidratado. Dissertação Universidade Federal de Ouro Preto. Ouro Preto, 87 p. 2008.

WANG, H. Q.; ZAO, Q.; ZENG, D-H.; HU, J. L.; YU, Z. J. Remediation of a MagnesiumContaminated Soil by Chemical Amendments and Leaching. Land Degradation \& Development, 26(6), 613619, 2015. 